42

The Open Biomarkers Journal
CrossMark
DOI: $10.2174 / 1875318301808010042,2018,8,42-46$

RESEARCH ARTICLE

\title{
Status of Ischemia Modified Albumin in Athletes Before and After Moderate Exercise
}

\author{
Kiran Dahiya ${ }^{1, *}$, Rajesh Kumar ${ }^{1}$, Rakesh Dhankhar ${ }^{2}$, Monica Verma ${ }^{1}$, Asha Kumari ${ }^{1}$, Prasanta Saha \\ Roy $^{1}$, Deepika Dalal ${ }^{1}$, Veena Singh Ghalaut ${ }^{1}$ and Kiran Chugh ${ }^{1}$ \\ ${ }^{I}$ Department of Biochemistry, Pt. BD Sharma University of Health Sciences, Haryana, India \\ ${ }^{2}$ Department of Radiotherapy, Pt. BD Sharma University of Health Sciences, Haryana, India
}

Received: August 23, 2018

Revised: November 20, 2018

Accepted: December 9, 2018

Abstract:

Background:

Ischemia Modified Albumin (IMA) is considered as an early marker of ischemia. Its levels may be altered in any clinical condition where an ischemic event is involved. Skeletal muscle ischemia is associated with severe exercise but may also occur in moderate form of exercise.

\section{Objective:}

The levels of IMA were estimated before and after thirty minutes of moderate exercise in students undergoing athletic training.

\section{Methods:}

The present study was conducted on 120 young adult students undergoing athletic training program in the physical education department. All the subjects were healthy with normal body mass index and blood pressure. Their serum samples were collected before and after running for half an hour on the racing track and were analyzed for IMA colorimetrically and the data was subjected to appropriate statistical analysis.

\section{Results:}

The levels of IMA were found to be statistically significantly higher after exercise as compared to those before exercise $(p=0.005)$. The ratio of IMA to albumin (IMAR) was also found to be significantly higher after exercise as compared to that before exercise $(\mathrm{p}=0.000)$.

\section{Conclusion:}

It may be concluded that the skeletal muscle ischemia induced by moderate aerobic exercise is associated with an increased conversion of albumin to IMA.

Keywords: Ischemia modified albumin, Skeletal muscle ischemia, Moderate exercise, Athletes, IMAR, Aerobic.

\section{INTRODUCTION}

Albumin is the most abundant plasma protein in humans. It is synthesized in liver, consists of 585 amino acid residues folded into three homologous domains. Albumin is synthesized in the form of preproalbumin, from which an $\mathrm{N}$-terminal peptide is removed converting it to proalbumin, which is released from the rough endoplasmic reticulum. Proalbumin, then, gets cleaved in the golgi vesicles to produce the secreted albumin [1]. On virtue of metal binding

* Address correspondence to this author at the Department of Biochemistry, Pt. BD Sharma University of Health Sciences, Haryana, India; Tel: 9896111985; E-mail: kirandahiya_2002@yahoo.com 
properties of albumin, metal ions are found to bind to a wide variety of sites, but the commonest one is N-terminus, comprising the sequence N-Asp-Ala-His-Lys [2]. Under ischemic conditions, it has been observed that there is reduced binding to $\mathrm{Co}^{2+}$ at this terminus and this modified albumin molecule is termed as Ischemia Modified Albumin (IMA). Because of this property, IMA acts as an early marker for myocardial ischemia [1]. The mechanism put forward for this modification of albumin includes production of free radicals on ischemia-reperfusion, which are strong oxidative compounds and affect the N-terminal portion of albumin [3]. Also there is substantial mobilization of iron and copper into the coronary flow immediately following prolonged cardiac ischemia which might also be responsible for this phenomenon [4].

Albumin is the most important and abundant plasma protein synthesized by the liver. A variety of posttranscriptional changes occur in the molecular structure of albumin producing different isoforms, IMA being one of them. IMA is now an upcoming biomarker as can be used to detect a number of clinical conditions associated with ischemia and oxidative stress. On changing to IMA, albumin molecule loses its physiological properties, hence, the ratio of IMA to albumin (IMAR) may prove to be more informative. The proportion getting modified to IMA will depend upon the ischemic stress the albumin molecule is subjected to [5].

Besides myocardial ischemia, other clinical conditions with an associated element of ischemia due to any reason have also shown elevated levels of IMA e.g pre-eclampsia, pregnancy, diabetic nephropathy, gastrointestinal or cerebral ischemia, intracranial haemorrhage, systemic sclerosis, and end stage renal disease etc [6 - 12]. Skeletal muscle ischemia has also been reported to lead to an increase in levels of IMA but these have been reported in marathon runners [13], after moderate and intense endurance training [14] or in experimentally induced forearm ischemia [15]. No reports could be found in literature to comment on the effect of short term moderate physical activity in athletes on the levels of IMA before and after exercise.

\section{MATERIALS AND METHODS}

This study was conducted in the Department of Biochemistry, Pt. BD Sharma University of Health Sciences, Rohtak in collaboration with Department of Physical Education, Maharshi Dayanand University, Rohtak. For this, 120 sportspersons undergoing different athletic training programs under this department were enrolled. All the subjects were healthy, were not on any kind of drug treatment or supplements. The subjects suffering from any kind of acute illness or with family history of any chronic illness were excluded from the study as ascertained by detailed history. Blood pressure, weight, height and waist circumference of all the subjects were recorded and Body Mass Index (BMI) was calculated using the formula weight/height ${ }^{2}$ and expressed as $\mathrm{Kg} / \mathrm{m}^{2}$. After collection of random blood sample in a plain vacutainer (Becton-Dickinson, Oxford, United Kingdom), each subject was asked to undergo moderate exercise/ physical activity in the form of running on the racing track of $400 \mathrm{~m}$ for a period of 30 minutes. Another blood sample was collected after completion of this moderate exercise program. All the samples were centrifuged and serum samples were analyzed for IMA and routine biochemistry investigations including glucose, liver function tests, renal function tests and cholesterol. Routine biochemistry parameters including total albumin were estimated on autoanalyzer ( $\mathrm{Rx}$ Suzuka, United Kingdom) using kits by Randox. IMA was estimated by colorimetric method using dithiothreitol and expressed as Absorbance Units (ABU) [16].

The results were compiled and analyzed using paired 'Student's t-test' and taking a value of $\mathrm{p}<0.05$ as significant.

A written informed consent was obtained from each subject and all the ethical issues were duly taken care of as per existing guidelines.

\section{RESULTS}

All the athletes were young adults with a mean age of $17.5 \pm 3.06$ years with the age range of 18-23years. All of them were studying in different colleges affiliated under the University. The male to female ratio was 11:1 with there being 10 females and 110 males. All were undergoing athletic training for a duration ranging from 6 months to 3 years. The mean height of the subjects was $170 \pm 7.15 \mathrm{~cm}$ and mean weight was $57.25 \pm 7.54 \mathrm{Kg}$ while mean BMI was found to be $19.5 \pm 1.96 \mathrm{Kg} / \mathrm{m}^{2}$. The mean waist circumference was recorded to be $74.15 \pm 3.6 \mathrm{~cm}$. All the subjects were nonsmokers and non-alcoholic in nature. Forty eight subjects $(40 \%)$ were vegetarian and rest $72(60 \%)$ were nonvegetarians. The past history and family history were uneventful for all of them. The serum levels of serum albumin, IMA and their ratio IMA/ albumin (IMAR) have been shown in Table 1. Serum IMA along with IMAR was found to be significantly increased after physical activity $(\mathrm{p}=0.005$ and 0.000 respectively). All the athletes had biochemical parameters and blood pressure within the normal range and no statistically significant difference was observed between 
pre and post-exercise levels ( $\mathrm{p}>0.05)$ (Table 2).

Table 1. Levels of IMA, albumin and IMAR in athletes before and after moderate exercise.

\begin{tabular}{|c|c|c|c|}
\hline- & Before Exercise & After Exercise & p Value \\
\hline Serum Albumin levels (g/dL) & $5.50 \pm 0.65$ & $5.59 \pm 0.36$ & 0.512 \\
\hline Serum IMA levels (ABU) & $0.65 \pm 0.03$ & $0.72 \pm 0.05$ & 0.005 \\
\hline IMA/ Albumin ratio (IMAR) & $0.116 \pm 0.02$ & $0.145 \pm 0.01$ & 0.000 \\
\hline
\end{tabular}

Table 2. Comparison of blood pressure and routine biochemistry parameters in athletes before and after exercise.

\begin{tabular}{|c|c|c|c|}
\hline- & Before Exercise & After Exercise & p Value \\
\hline Blood pressure (mmHg) & $118 \pm 6.2$ & $120 \pm 4.3$ & 0.21 \\
\hline Glucose $(\mathrm{mg} / \mathrm{dL})$ & $92.10 \pm 15.57$ & $90.17 \pm 12.08$ & 0.002 \\
\hline Urea (mg/dL) & $29.68 \pm 8.5$ & $31.65 \pm 7.1$ & 0.04 \\
\hline Creatinine (mg/dL) & $1.04 \pm 0.16$ & $1.13 \pm 0.15$ & 0.003 \\
\hline Uric acid (mg/dL) & $6.15 \pm 1.95$ & $5.65 \pm 1.98$ & 0.01 \\
\hline Calcium (mg/dL) & $10.37 \pm 0.63$ & $10.12 \pm 0.63$ & 0.01 \\
\hline Phosphorus (mg/dL) & $4.66 \pm 0.73$ & $5.11 \pm 0.63$ & 2.14 \\
\hline Aspartate transaminase (U/L) & $46.05 \pm 12.65$ & $45.77 \pm 14.69$ & 0.86 \\
\hline Alanine transaminase (U/L) & $34.45 \pm 23.61$ & $34.89 \pm 24.49$ & 0.93 \\
\hline Alkaline phosphatase (U/L) & $135.25 \pm 85.71$ & $106.19 \pm 52.77$ & 0.05 \\
\hline Total Protein (g/dL) & $8.83 \pm 1.19$ & $8.11 \pm 0.54$ & 0.24 \\
\hline Cholesterol (mg/dL) & $163.66 \pm 25.43$ & $158.91 \pm 27.06$ & 0.11 \\
\hline
\end{tabular}

\section{DISCUSSION}

In the present study, IMA was found to be significantly raised in athletes after moderate exercise $(p=0.005)$. Exercise leads to some metabolic and physiologic changes in skeletal muscles bringing about ischemia like conditions [17]. IMA is a proven early cardiac marker of myocardial ischemia but it is not specific for cardiac tissue only [15]. Any tissue undergoing ischemic condition, may lead to modification of albumin to IMA. This change is associated with hypoxia, acidosis and free radical damage caused by ischemia which may alter the ability of three amino acids (aspartate, alanine, and histidine) at the N-terminus of albumin to bind free metal atoms, including cobalt [18].

Similar results have been observed by other authors under surgically induced ischemic conditions including major arterial surgical procedure [19] and orthopedic surgeries [3]. The short duration physical activity model should be most suitable for observing its effect on IMA based on the short time kinetics observed for increase in its levels. The levels increase within minutes of an episode of ischemia and return to baseline in no longer than 12 hours [15]. Therefore, long duration ischemia as seen in marathon runners does not appear to be appropriate to investigate the effect of ischemia on IMA levels. In a study on marathon runners, the significant increase in IMA levels was observed after 24-48 hours but immediately post-race, the levels were found to be within the reference range. The researchers ruled out the origin of IMA being myocardial tissue by cardiac troponin $\mathrm{T}$ and attributed this rise to either gastrointestinal or skeletal muscle ischemia [13]. In a study on cyclists and skiers after high endurance training, the subjects were observed to demonstrate significantly higher IMA levels in high workload training only as compared to healthy but sedentary controls. No significant change was observed in the levels of cardiac troponin T ruling out the component of myocardial ischemia in these subjects too [14].

There are few studies in literature which report a decrease in IMA levels immediately after exercise. They attributed it to an increase in total albumin due to hemoconcentration as well as to transport increased fatty acids available. This produces an increased cobalt binding masking the altered binding properties of IMA [20, 21].

In the present research, total albumin was found to be increased but not statistically significantly after moderate physical activity as compared to levels before it. To normalize the effect of albumin levels, the ratio of IMA to albumin (IMAR) was calculated and was found to be significantly increased in these athletes after running than the levels before physical activity $(p=0.000)$. Increased IMA levels in pre-eclampsia were found to be associated with increased IMAR in other studies carried out in diverse medical conditions [22, 23]. 
Regular physical activity has a variety of health benefits decreasing the overall mortality but contracting skeletal muscles generate free radicals resulting in oxidative damage to cellular constituents. Moreover, the associated lactic acidosis also may be involved in conversion of albumin to IMA [24].

\section{CONCLUSION}

It may be concluded that skeletal muscle ischemia associated with moderate physical activity leads to increased production of IMA. Thus, IMA, which was earlier thought to be an early cardiac marker for myocardial ischemia only, may be used as a marker of ischemia in other tissues also. This knowledge may help to understand the molecular and physiological changes associated with exercise in a better way.

\section{CURRENT AND FUTURE DEVELOPMENTS}

IMA is an established marker for cardiac ischemia and helps in detecting myocardial infarction at a very early stage. But recently, it has been found to be useful in the detection of other ischemic conditions in the body. This research indicates towards association of skeletal muscle ischemia even with moderate exercise and may open avenues for further research in this direction and may help in better understanding of the physiology of exercise with future implications.

\section{ETHICS APPROVAL AND CONSENT TO PARTICIPATE}

This study was conducted in the Pandit Bhagwat Dayal Sharma University of Health Sciences Rohtak in collaboration with Maharshi Dayanand University, Rohtak and all the ethical issues were duly taken care of as per existing guidelines.

\section{HUMAN AND ANIMAL RIGHTS}

No Animals were used in this research. All human research procedures followed were in accordance with the ethical standards of the committee responsible for human experimentation (institutional and national), and with the Helsinki Declaration of 1975, as revised in 2013.

\section{CONSENT FOR PUBLICATION}

Informed consent was taken from all the patients when they were enrolled.

\section{CONFLICT OF INTERESTS}

The authors declare no conflict of interest, financial or otherwise.

\section{ACKNOWLEDGEMENTS}

The contribution and co-operation of Department of Physical Education, Maharshi Dayanand University, Rohtak is duly acknowledged.

\section{REFERENCES}

[1] Dahiya K, Aggarwal K, Seth S, Singh V, Sharma TK. Type 2 diabetes mellitus without vascular complications and ischemia modified albumin. Clin Lab 2010; 56(5-6): 187-90. [PMID: 20575465]

[2] Dahiya K, Verma M, Dhankhar R, Singh V, Ghalaut PS, Seth S. Alteration of ischemia modified albumin and nitric oxide levels in hypothyroidism. Clin Lab 2014; 60(6): 969-72. [PMID: 25016702]

[3] Refaai MA, Wright RW, Parvin CA, Gronowski AM, Scott MG, Eby CS. Ischemia-modified albumin increases after skeletal muscle ischemia during arthroscopic knee surgery. Clin Chim Acta 2006; 366(1-2): 264-8. [http://dx.doi.org/10.1016/j.cca.2005.10.020] [PMID: 16337614]

[4] Worster A, Devereaux PJ, Heels-Ansdell D, et al. Capability of ischemia-modified albumin to predict serious cardiac outcomes in the short term among patients with potential acute coronary syndrome. CMAJ 2005; 172(13): 1685-90. [http://dx.doi.org/10.1503/cmaj.045194] [PMID: 15967971]

[5] Yavuz F, Biyik M, Asil M, et al. Serum ischemic modified albumin (IMA) concentration and IMA/albumin ratio in patients with hepatitis Brelated chronic liver diseases. Turk J Med Sci 2017; 47(3): 947-53. [http://dx.doi.org/10.3906/sag-1611-66] [PMID: 28618749] 
[6] Dahiya K, Kulshrestha MR, Bansal P, et al. Evaluation of cord blood ischemia modified albumin in normal pregnancies and pre-eclampsia. Hypertens Pregnancy 2015; 34(2): 204-8. [http://dx.doi.org/10.3109/10641955.2014.1001901] [PMID: 25775261]

[7] van Rijn BB, Franx A, Sikkema JM, van Rijn HJ, Bruinse HW, Voorbij HA. Ischemia modified albumin in normal pregnancy and preeclampsia. Hypertens Pregnancy 2008; 27(2): 159-67. [http://dx.doi.org/10.1080/10641950701885147] [PMID: 18484421]

[8] Dahiya K, Kumawat M, Kaur R, et al. Ischemia modified albumin and nitric oxide in diabetic nephropathy. J Diabetol 2013; 1: 1.http://www.journalofdiabetology.org/

[9] Gunduz A, Turedi S, Mentese A, et al. Ischemia-modified albumin levels in cerebrovascular accidents. Am J Emerg Med 2008; 26(8): 874-8. [http://dx.doi.org/10.1016/j.ajem.2007.11.023] [PMID: 18926343]

[10] Abboud H, Labreuche J, Meseguer E, et al. Ischemia-modified albumin in acute stroke. Cerebrovasc Dis 2007; 23(2-3): 216-20. [http://dx.doi.org/10.1159/000097644] [PMID: 17143006]

[11] Borderie D, Allanore Y, Meune C, Devaux JY, Ekindjian OG, Kahan A. High ischemia-modified albumin concentration reflects oxidative stress but not myocardial involvement in systemic sclerosis. Clin Chem 2004; 50(11): 2190-3. [http://dx.doi.org/10.1373/clinchem.2004.034371] [PMID: 15502098]

[12] Cichota LC, Moresco RN, Duarte MM, da Silva JE. Evaluation of ischemia-modified albumin in anemia associated to chronic kidney disease. J Clin Lab Anal 2008; 22(1): 1-5.

[http://dx.doi.org/10.1002/jcla.20226] [PMID: 18200583]

[13] Apple FS, Quist HE, Otto AP, Mathews WE, Murakami MM. Release characteristics of cardiac biomarkers and ischemia-modified albumin as measured by the albumin cobalt-binding test after a marathon race. Clin Chem 2002; 48(7): 1097-100. [PMID: 12089181]

[14] Lippi G, Brocco G, Salvagno GL, Montagnana M, Dima F, Guidi GC. High-workload endurance training may increase serum ischemiamodified albumin concentrations. Clin Chem Lab Med 2005; 43(7): 741-4. [http://dx.doi.org/10.1515/CCLM.2005.126] [PMID: 16207135]

[15] Zapico-Muñiz E, Santaló-Bel M, Mercé-Muntañola J, Montiel JA, Martínez-Rubio A, Ordóñez-Llanos J. Ischemia-modified albumin during skeletal muscle ischemia. Clin Chem 2004; 50(6): 1063-5. [http://dx.doi.org/10.1373/clinchem.2003.027789] [PMID: 15161723]

[16] Bar-Or D, Lau E, Winkler JV. A novel assay for cobalt-albumin binding and its potential as a marker for myocardial ischemia-a preliminary report. J Emerg Med 2000; 19(4): 311-5. [http://dx.doi.org/10.1016/S0736-4679(00)00255-9] [PMID: 11074321]

[17] Duman C, Çolak T, Bamaç B, Göker I, Çolak S, Özbek A. Ischemia-modified albumin levels in professional male soccer players before and after training. Marmara Med J 2013; 26: 21-4.

[18] Christenson RH, Duh SH, Sanhai WR, et al. Characteristics of an albumin cobalt binding Test for assessment of acute coronary syndrome patients: A multicenter study. Clin Chem 2001; 47(3): 464-70. [PMID: 11238298]

[19] Troxler M, Thompson D, Homer-Vanniasinkam S. Ischaemic skeletal muscle increases serum ischaemia modified albumin. Eur J Vasc Endovasc Surg 2006; 31(2): 164-9.

[http://dx.doi.org/10.1016/j.ejvs.2005.06.019] [PMID: 16081305]

[20] Middleton N, Shave R, George K, et al. Novel application of flow propagation velocity and ischaemia-modified albumin in analysis of postexercise cardiac function in man. Exp Physiol 2006; 91(3): 511-9. [http://dx.doi.org/10.1113/expphysiol.2005.032631] [PMID: 16431933]

[21] Roy D, Quiles J, Sharma R, et al. Ischemia-modified albumin concentrations in patients with peripheral vascular disease and exercise-induced skeletal muscle ischemia. Clin Chem 2004; 50(9): 1656-60. [http://dx.doi.org/10.1373/clinchem.2004.031690] [PMID: 15265817]

[22] D'souza JMP, Pai VR, Harish S, Shriyan C, D’souza N. IMA and IMAR in serum and saliva of preeclampsia-A preliminary study. Hypertens Pregnancy 2014; 33(4): 440-8.

[http://dx.doi.org/10.3109/10641955.2014.931418] [PMID: 25019475]

[23] Reddy SV, Suchitra MM, Pradeep V, et al. Ischemia-modified albumin levels in overt and subclinical hypothyroidism. J Endocrinol Invest 2015; 38(8): 885-90. [http://dx.doi.org/10.1007/s40618-015-0283-x] [PMID: 25862649]

[24] Powers SK, Jackson MJ. Exercise-induced oxidative stress: Cellular mechanisms and impact on muscle force production. Physiol Rev 2008; 88(4): 1243-76.

[http://dx.doi.org/10.1152/physrev.00031.2007] [PMID: 18923182]

\section{(C) 2018 Kiran Dahiya.}

This is an open access article distributed under the terms of the Creative Commons Attribution 4.0 International Public License (CC-BY 4.0), a copy of which is available at: (https://creativecommons.org/licenses/by/4.0/legalcode). This license permits unrestricted use, distribution, and reproduction in any medium, provided the original author and source are credited. 